\title{
Predation on eggs of Schneider's dwarf caiman, Paleosuchus trigonatus (Schneider, 1807), by armadillos and other predators
}

\author{
Z. Camposa , F. Muniz ${ }^{\text {, A. L. J Desbiez }{ }^{c} \text { and W. E. Magnusson }}{ }^{b}$ \\ aLaboratório de vida selvagem, Embrapa Pantanal, Corumbá, Brazil; 'bepartamento de Ecologia, INPA, \\ Manaus, Brazil; 'Conservation Department, Royal Zoological Society of Scotland, Scotland, UK
}

\begin{abstract}
Nests of Schneider's dwarf caiman, Paleosuchus trigonatus, were located in the forests around three streams that drain into the Xingu River, Brazilian Amazonia, in October 2014. Camera traps were installed at the edge of four nests to document predators and female parental care. At two nests, females unsuccessfully defended their nests against one or more giant armadillos, Priodontes maximus, and nine-banded armadillos, Dasypus novemcinctus. Both armadillo species responded to the attack by fleeing and returning on the opposite side of the nest by going around the tree under which the nest was located. Giant armadillos have never before been recorded consuming caiman eggs and their diet has been described as consisting mostly of ants and termites. Another species of armadillo, Cabassous unicinctus, was also registered digging into a nest and probably consuming eggs, though it is generally considered to be primarily insectivorous. A tayra (Eira barbara), lizard (Tupinambis teguixin) and coati (Nasua nasua) were also registered taking eggs from nests during the day, but we obtained no registers of nest defence by caimans during the day. The three nests were attacked after 60 days of incubation, when the eggs were well developed.
\end{abstract}

\section{ARTICLE HISTORY}

Received 20 October 2015 Accepted 21 January 2016 Online 11 April 2016

\section{KEYWORDS}

Parental care; armadillos; predation; Amazonia

\section{Introduction}

Female crocodilians defend their nests from predators (Lang 1987), and autonomous cameras have allowed documentation of nest predation and parental care in many species of crocodilians (Magnusson 1982; Villamarin-Jurado and Suárez 2007; Da Silveira et al. 2010; Charruau and Hénaut 2012; Elsey et al. 2012; Campos and Mourão 2015; Mazzotti et al. 2015). However, there has been little information on predators of eggs of Schneider's dwarf caiman or female defence of nests in this species.

Schneider's dwarf caiman, Paleosuchus trigonatus, has a long incubation period, which can be over 100 days (Magnusson 1992). Parental care of recently hatched young has been described as short, as they disperse around 1 week after hatching (Magnusson and Lima 1991). On the other hand, parental care has been described for the dwarf caiman,

CONTACT Z. Campos zilca.campos@embrapa.br Embrapa Pantanal, Laboratório de vida selvagem, CP 109 Corumbá, MS 79320-900 Brazil 
Paleosuchus palpebrosus (Campos and Sanaiotti 2006), with care for the hatchlings lasting for up to 12 months (Campos et al. 2012). Nothing is known about parental care or nest defence of Schneider's dwarf caiman during the period of egg incubation. We used camera traps to document nest predators and female behaviour in the forest streams of the Xingu River, Brazilian Amazonia.

\section{Materials and methods}

In October 2014, we searched by foot for nests of Schneider's dwarf caimans in the forests around three streams that drain into the Xingu River, Pará, Brazil ( $3^{\circ} 24^{\prime} S, 51^{\circ} 99^{\prime}$ W). Four nests were encountered and opened to count the eggs. Eggs were replaced and the nest closed, except for one egg that was collected from each nest to estimate the age of the embryo using a table for $P$. trigonatus published by Ruesta (1982). All the nests were found against trunks or buttress roots of trees that had termite mounds near them. No adult caiman was seen near the nests when they were encountered. The number of eggs in nests varied between 12 and 19, and the embryos were on average $7.7 \mathrm{~cm}$ [standard deviation (SD) $=1.65$ ] in total length, indicating they had been laid around 1 October 2014 (Ruesta 1982). In front of each nest we installed digital camera traps (Bushnell Trophy Cam ${ }^{\circledR}$ Kansas City, MO, USA) to register images of predators as well as the potential presence of the female caiman at the nest. Cameras were programmed to take pictures when activated by a motion sensor.

\section{Results}

One nest was attacked by a giant armadillo, Priodontes maximus, and a Cabassous unicinctus. A giant armadillo was registered 2 December 2014 at $0359 \mathrm{hrs}$ and remained at the nest for almost 12 minutes, during which time it ate 12 eggs with embryos estimated to be 63 days old. A female caiman was photographed for $30 \mathrm{~s}$ in various attack postures towards the giant armadillo, starting at $0412 \mathrm{hrs}$. The giant armadillo ran away from her, but returned to the nest by going around a tree (Figure 1); however, it did not predate more eggs.

On 11 December 2014, we inspected the nest and only found five intact eggs and no remains of other eggs. On 23 December 2014 at 0522 hrs, a giant armadillo was photographed digging into the nest, and probably consumed the five remaining eggs. After 2 minutes, an adult caiman was registered defending the nest against a giant armadillo, which seemed to stand up to it before leaving (Figure 2). An individual of another species of armadillo, Cabassous unicinctus, was photographed digging into the nest on 25 December 2014 at 0430 hrs, where it stayed for 3 minutes, but we could not see whether it ate any eggs. We believe the giant armadillo had already consumed the remaining eggs. The adult female caiman did not appear.

A second nest had 19 eggs with embryos estimated to be 64 days old when a ninebanded armadillo first attacked this nest on 14 December 2014 at 2341 hrs. The same species was recorded attacking the nest on 17 December 2014 at 2141 hrs, and 20 December 2014 at 2043 hrs, without evidence of an adult caiman. However, on 29 December 2014 at 2156 hrs, an adult caiman appeared for 2 minutes and chased the armadillo, which ran away by going behind a tree before reappearing on the other side 

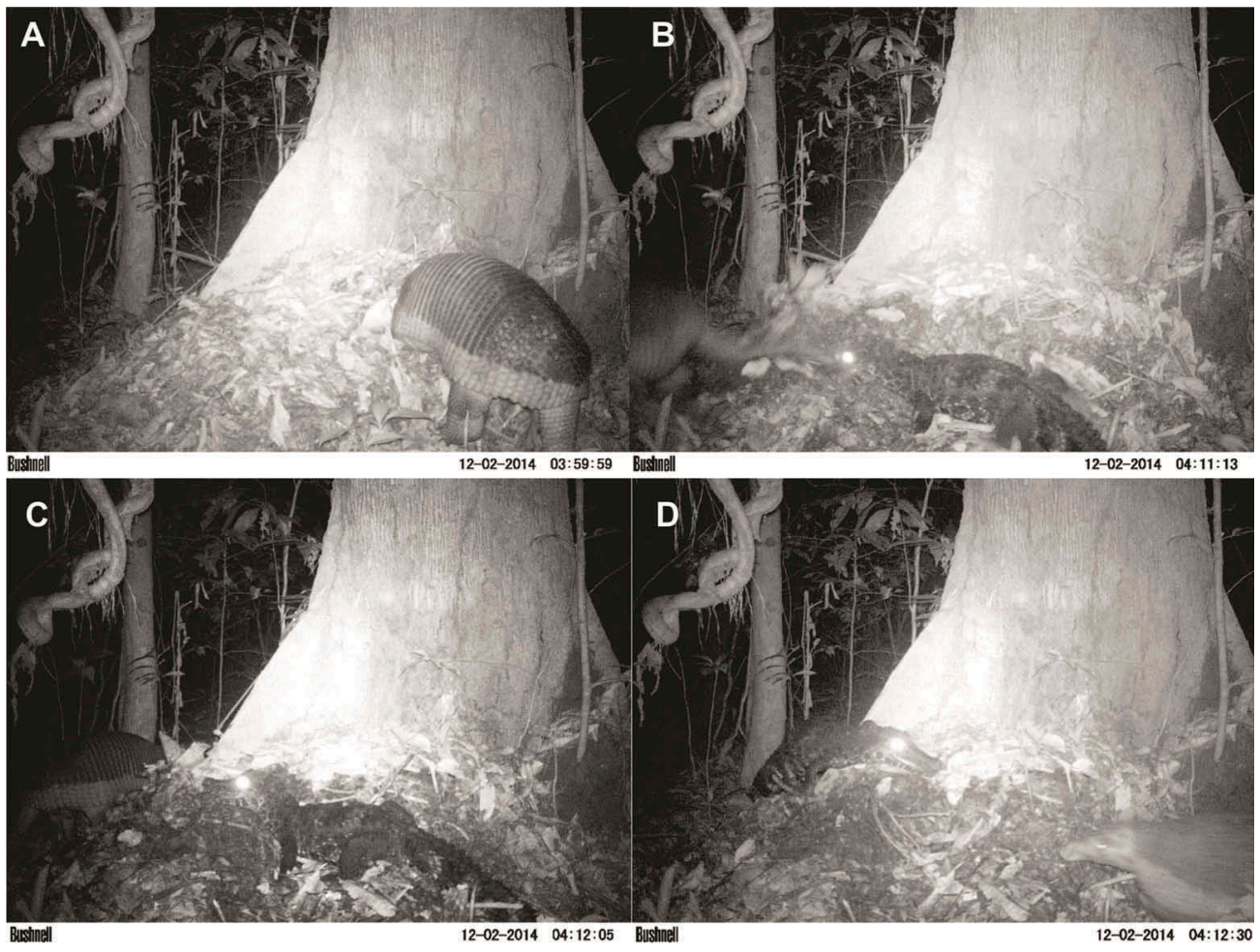

Figure 1. (A) Giant armadillo eats eggs, $(\mathrm{B}, \mathrm{C})$ female Paleosuchus trigonatus defends the nest and (D) the giant armadillo returns to the nest after retreating behind the tree.

(Figure 3). He did not continue predating the nest. A nine-banded armadillo was recorded at the same nest on 1 January 2015 at 0401 hrs, where it remained for 3 minutes digging and consuming eggs. On the same day, at $1325 \mathrm{hrs}$, a lizard (Tupinambis teguixin) was photographed with an egg in its mouth, and a tayra (Eira barbara) was registered digging into the nest and consuming eggs for 7 minutes at $1511 \mathrm{hrs}$.

The third nest had 12 eggs and embryos 77 days old when it was attacked by a coati (Nasua nasua) on 28 December 2014 for 12 minutes. A lizard (Tupinambis teguixin) ate the rest of the eggs 2 days later, between 1235 and 1242 hrs.

No predators or caimans were recorded at a fourth nest, and the 17 eggs hatched after about 95 days of incubation, assuming that they were laid on 1 October 2014.

\section{Discussion}

Female crocodilians often remain near nest sites, or on top of their nest to protect it, and this is thought to minimise the frequency of predatory attacks (Lang 1987; Campos 1993; Campos and Sanaiotti 2006; Campos et al. 2008). However, Schnieder's dwarf caimans have not previously been reported attending nests (Magnusson et al. 1985, 1990). This is the first study to document the presence of adult female caimans at nests, and defensive attacks on predators by Schneider's dwarf caiman. 

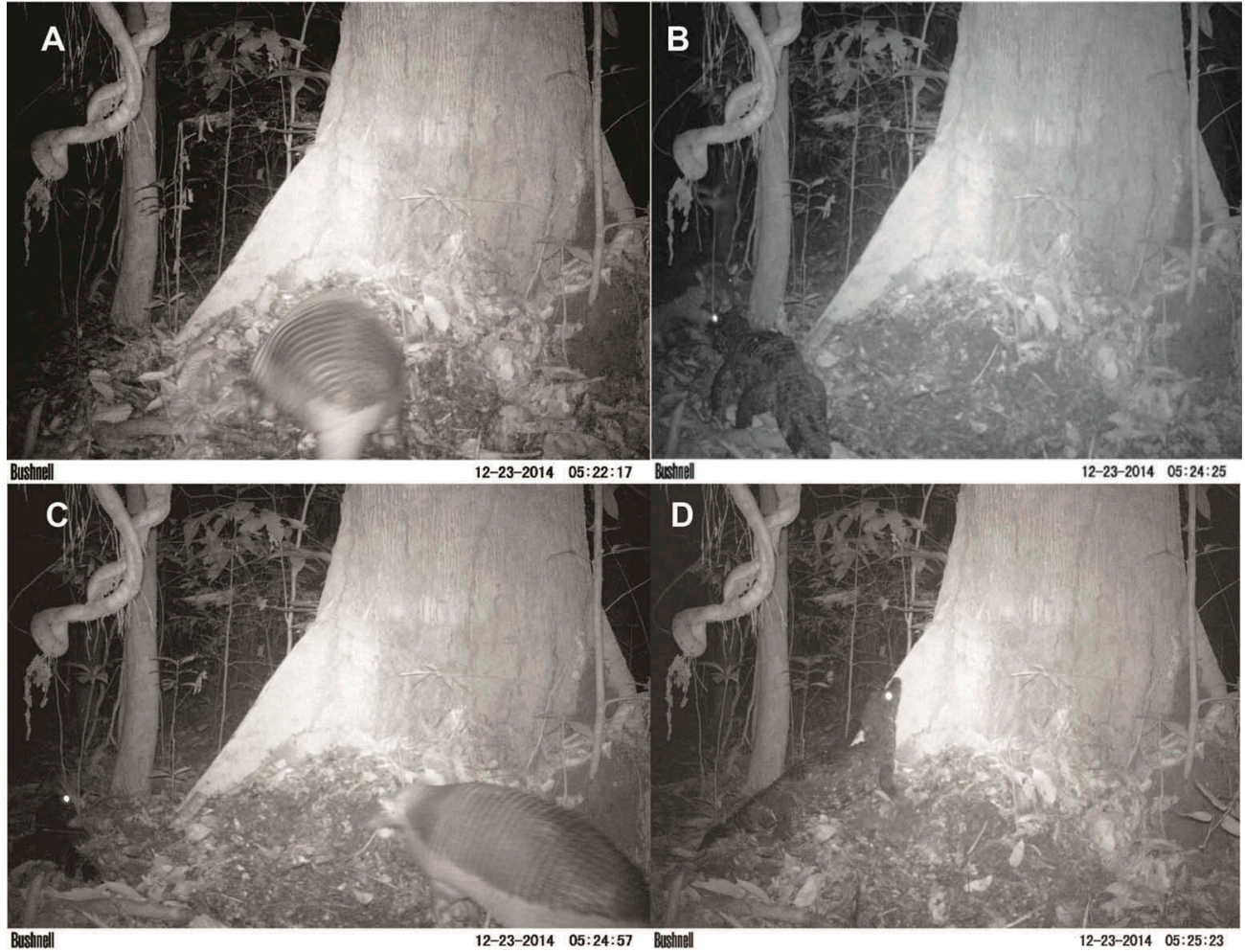

Figure 2. After 21 days, (A) a giant armadillo returns to the same nest and is driven away by an adult Paleosuchus trigonatus. After (B) remaining face to face with the caiman, $(C, D)$ the armadillo departs, circling the nest tree.

The adult caimans, presumably the females that had made the nests, were registered attacking species of armadillos during the night after the predator started digging into the nest. Adult caimans were not seen near the nests when they were located during the day, but they must remain nearby, especially at night. We did not register caimans attempting to protect the eggs from coati (Nasua nasua), tayra (Eira barbara) or lizards (Tupinambis teguixin), which attacked the nest during the day. We are not sure why we registered female defensive attacks only at night. The embryos were over 60 days old at the time of the attacks, and in all cases it was more than 40 days since the nests had been opened by researchers.

Nine-banded armadillos have been reported eating eggs of Caiman crocodilus yacare in the Pantanal towards the end of the incubation period (Campos and Mourão 2015). However, the diet of giant armadillos has been described as consisting almost exclusively of insects, mainly ants and termites, though some fruit has been reported (Anacleto and Marinho-Filho 2001; Wallace and Painter 2013). To our knowledge this is the first report of the species eating eggs, in this case Schneider's dwarf caiman eggs.

During the attack, the giant armadillo apparently confronted the female and returned to the nest but was not registered predating anymore. Both the giant armadillo and the nine-banded armadillo reacted similarly to the attack by the female: they backed off and then returned to the nest from behind a tree. We are not sure if the Cabassous unicinctus 

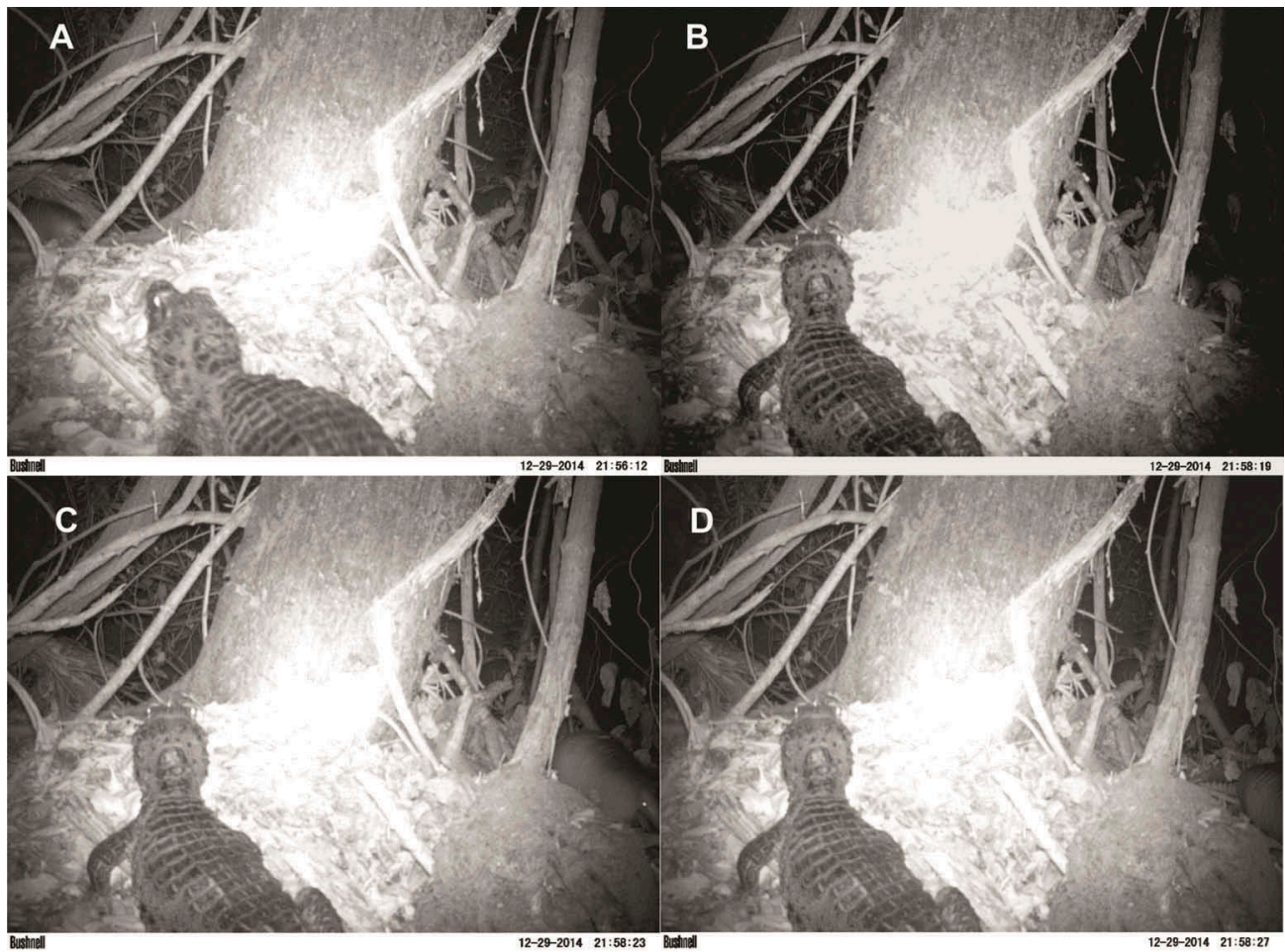

Figure 3. (A, B) Adult Paleosuchus trigonatus defends a nest against a nine-banded armadillo, Dasypus novemcinctus, which (C, D) leaves, then returns by going around the nest tree.

we registered digging into the nest consumed eggs. Little is known about this species, and it is believed to feed mainly on insects and termites (Eisenberg and Redford 1989).

The armadillos ate eggs that were over 60 days old and had well-developed embryos. Predation on caiman nests by armadillos has previously only been reported for Caiman crocodilus yacare. However, the overlap between the distributions of Neotropical crocodilians and the number of armadillo species involved indicates that armadillo predation on caiman nests is likely to be more common than the scarce records would indicate.

\section{Acknowledgements}

This work was supported by the Norte Energia, Leme Engenharia and Fundação Pantanal Com Ciência. We thank Daniel Martins, Reginey Gomes, Roberto da Costa, Elenilson Silva, Fernando Costa and Sebastião Gama for their help in finding nests and for help with the camera traps. Rosilene Gutierrez helped with photo quality. The study was undertaken under permit number 13048-1 from the Brazilian Institute of Environment and Renewable Natural Resources (IBAMA).

\section{Disclosure statement}

No potential conflict of interest was reported by the authors. 


\section{References}

Anacleto TCS, Marinho-Filho JS. 2001. Hábito alimentar do tatu-canastra (Xenarthra, Dasypodidae) em uma área de cerrado do Brasil Central. Revista Brasileira de Zoologia. 18:681-688.

Campos Z. 1993. Effect of habitat on survival of eggs and sex ratio of hatchlings of Caiman crocodilus yacare in the Pantanal, Brazil. J Herpetol. 27:127-132.

Campos Z, Magnusson W, Sanaiotti T, Coutinho M. 2008. Reproductive trade-offs in Caiman crocodilus crocodilus and Caiman crocodilus yacare: implications for size-related management quotas. Herpetol J. 18:91-96.

Campos Z, Mourão G. 2015. Camera traps capture images of predators of Caiman crocodilus yacare eggs (Reptilia: Crocodylia) in Brazil's Pantanal wetlands. J Nat Hist. 49:977-982.

Campos Z, Sanaiotti T. 2006. Paleosuchus palpebrosus (Dwarf caiman) Nesting. Herpet Rev. 37:81.

Campos Z, Sanaiotti T, Muniz F, Farias I, Magnusson WE. 2012. Parental care in the dwarf caiman, Paleosuchus palpebrosus Cuvier, 1807 (Reptilia: Crocodilia: Alligatoridae). J Nat Hist. 46:29792984.

Charruau P, Hénaut Y. 2012. Nest attendance and hatchling care in wild American crocodiles (Crocodylus acutus) in Quintana Roo, Mexico. Anim Biology. 62:29-51.

Da Silveira R, Ramalho EE, Thorbjarnarson JB, Magnusson WE. 2010. Depredation by jaguars on caiman and importance of reptiles in the diet of jaguar. J Herpetol. 44:418-424.

Eisenberg JF, Redford KH. 1989. Mammals of the neotropics. Chicago (IL): University of Chicago; Vol. 3. 609p.

Elsey R, Mouton Jr EC, Kinler N. 2012. Effects of feral swine (Sus scrofa) on Alligator (Alligator mississippiensis) in nests in Louisiana. Southwest Nat. 11:205-218.

Lang JW. 1987. Crocodilian behavior: implications for management. In: Webb GJW, Manolis SC, Whitehead PJ, editors. Wildlife management: crocodiles and alligator. Chippping Norton (NSW): Surrey Beatty and Sons PTY Limited; p. 273-294.

Magnusson W, Lima AP, Hero JM, Sanaiotti TM, Yamakoshi M. 1990. Paleosuchus trigonatus nests: sources of heat and embryo sex ratios. J Herpetol. 24:397-400.

Magnusson W, Lima AP, Sampaio RM. 1985. Sources of heat for nests of Paleosuchus trigonatus and a review of crocodilian nest temperatures. J Herpet. 19:199-207.

Magnusson WE. 1982. Mortality of eggs of the crocodile Crocodylus porosus in Northern Australia. J Herpetol. 16:121-130.

Magnusson WE. 1992. Paleosuchus trigonatus. CAAR. 555:1-3.

Magnusson WE, Lima AP. 1991. The Ecology of a Cryptic Predator, Paleosuchus tigonatus, in a Tropical Rainforest. J Herpetol. 25:41-48.

Mazzotti F, McEachern M, Rochford M, Reed RN, Eckles JK, Vinci J, Edwards J, Wasilewski J. 2015. Tupinambis merianae as nest predators of crocodilians and turtles in Florida, USA. Biological Invasions. 17:47-50.

Ruesta PGV. 1982. Descripcion del desarrollo embrionario de Paleosuchus trigonatus Schneider em pequena, Loreto. Revista Forestal del Peru. XI:195-201.

Villamarin-Jurado F, Suárez E. 2007. Nesting of the black caiman (Melanosuchus niger) in Northeastern Ecuador. J Herpet. 41:164-167.

Wallace RB, Painter LE. 2013. Observations on the Diet of the Giant Armadillo (Priodontes maximus Kerr, 1972). Edentata. 14:85-86. 